\title{
Determination of the tension softening curve of nuclear graphites using the incremental displacement collocation method
}

\author{
R.K.L. Su ${ }^{1,}$, H.H. Chen ${ }^{1}$, S.L. Fok ${ }^{2}$, H. Li ${ }^{2}$, G. Singh ${ }^{2}$, L. Sun ${ }^{3}$ and L. Shi ${ }^{3}$ \\ ${ }^{1}$ Department of Civil Engineering, The University of Hong Kong, PRC \\ ${ }^{2}$ School of Dentistry, University of Minnesota, USA \\ ${ }^{3}$ Division of Reactor Structure, The Institute of Nuclear and New Energy Technology, \\ Tsinghua University, PRC
}

\begin{abstract}
The fracture properties of two nuclear-grade graphites, the Japanese IG11 graphite and Chinese NG-CT-01 graphite, were evaluated under flexural conditions. Three-point bend tests were performed on centre-notched beams to determine the tension softening curve (TSC), Mode-I fracture toughness $K_{I C}$ and the fracture energy $G_{F}$. The TSC of the nuclear graphites was originally determined by a newly developed incremental displacement collocation method, and was shown to be able to predict the post-peak behaviour accurately. The TSC was simplified to the bilinear, tri-linear and exponential curves. The tri-linear curve was found to be the best approximation for modelling the tension softening of these nuclear graphites. Furthermore, scanning electron microscope images of their microstructures showed that the difference in brittleness and fracture behavior between the two graphites was probably caused by a difference in grain size and the degree of binder infiltration.
\end{abstract}




\section{Symbols}

\begin{tabular}{|c|c|}
\hline$K_{\text {Ic }}$ & Mode-I fracture toughness \\
\hline$G_{F}$ & fracture energy \\
\hline$G_{F}^{P-\delta}$ & fracture energy obtained from the load-deflection curve \\
\hline$G_{F}^{T S C}$ & fracture energy obtained from the tension softening curve \\
\hline$A_{0}$ & area under the measured load-deflection curve \\
\hline$L$ & length of the beam \\
\hline$S$ & span of the beam \\
\hline$b$ & depth of the beam \\
\hline$t$ & thickness of the beam \\
\hline$a_{0}$ & initial notch depth \\
\hline$\Delta a$ & length of the propagating crack \\
\hline E & Young's modulus \\
\hline$f_{t}$ & tensile strength of the material \\
\hline$P$ & applied load \\
\hline$P_{c}$ & critical load at the peak load \\
\hline$\delta_{c}$ & deflection at the peak load \\
\hline$N M O D_{c}$ & critical notch mouth opening displacement at the peak load \\
\hline$N T O D_{c}$ & critical notch tip opening displacement at the peak load \\
\hline$\sigma$ & cohesive stress \\
\hline$\sigma_{\max }$ & the maximum calculated stress \\
\hline$w$ & crack opening width \\
\hline$w_{C}$ & characteristic crack width corresponding to $\sigma(w)=0$ \\
\hline$P_{i}$ & applied load at the $i^{\text {th }}$ step \\
\hline$\sigma_{i}$ & trial cohesive stress to be determined at the $i^{\text {th }}$ step \\
\hline
\end{tabular}


$w_{i} \quad$ crack opening corresponding to the cohesive stress $\sigma_{i}$

$l_{p i} \quad$ length of the cohesive crack at the $i^{\text {th }}$ step

$d_{e} \quad$ experimental displacement

$\delta_{e} \quad$ experimental mid-span deflection

$\mathrm{NMOD}_{e} \quad$ experimental notch mouth opening displacement of graphite beam

$\mathrm{NTOD}_{e} \quad$ experimental notch tip opening displacement of graphite beam

$d_{n} \quad$ numerical displacement

$\delta_{n} \quad$ numerical mid-span deflection

$\mathrm{NMOD}_{n} \quad$ numerical notch mouth opening displacement of graphite beam

$\mathrm{NTOD}_{n} \quad$ numerical notch tip opening displacement of graphite beam

\section{Acronyms}

CCM cohesive crack model

TSC tension softening curve

FEM finite element model

ESPI electronic speckle pattern interferometry

FPZ fracture process zone

COD crack opening displacement

NMOD notch mouth opening displacement

NTOD notch tip opening displacement

SEM Scanning electron microscope 


\section{Introduction}

Due to its effectiveness in slowing down fast neutrons from nuclear fission and its excellent thermal properties, graphite is widely used as a moderator to sustain the chain reaction in nuclear reactors. However, being quasi-brittle, it is mechanically weak [1]. Therefore, components made of graphite may fracture under impact loads such as those seen in a seismic event. In addition, during operation, the neutron irradiation causes the graphite components to undergo property and dimensional changes which can generate fracture-causing stresses within them [2]. For these reasons, the fracture behaviour of graphite must be considered.

It is well known that the microstructure plays a dominant role in controlling the fracture behaviour of graphite [3]: with a higher mean particle size and density, and a smaller mean pore size, the tensile strength of graphite increases. Neutron irradiation and other ageing mechanisms can significantly change graphite’s microstructure and, hence, its mechanical properties. For example, the bend strength of graphite is reduced by both thermal and radiolytic oxidation [4]. Hodgkins et al. [5] found that radiolytic oxidation increased the proportion of porosity so that the microstructure became increasingly skeletal with an associated loss of strength. While the elastic modulus and flexural strength of graphite showed an initial increase with neutron irradiation, both of them decrease at high irradiation due to the increase in voids 
[6].Yoda et al. [7] found that Young's modulus of graphite decreased with increasing applied stress as a result of increased pore volume. In addition, the tensile strength and Young’s modulus of graphite may be influenced by temperature [8].

Numerous investigations have been carried out to understand the deformation and fracture mechanisms of graphite [9]; with some considering the initiation of fracture in unnotched specimens while others investigating the crack propagation of pre-notched or cracked components. Only a few have focused on the fracture properties of graphite that are essential for determining both the crack initiation and crack propagation criteria of graphite [10]. The crack initiation criteria for graphite are typically based on the strength of materials theory, while the crack propagation criteria are traditionally based on linear elastic fracture mechanics. More recently, graphite was found to exhibit a nonlinear, inelastic stress-strain response from damage accumulation [11]. Hodgkins et al. [12], when investigating the crack propagation in nuclear graphite using X-ray microtomography, showed that graphite exhibited a “quasi-brittle” behavior due to the distributed microcracks in a damage zone [5]. Therefore, nonlinear fracture mechanics must be used to fully characterise the fracture behaviour of graphite [12].

A continuum damage mechanics model, which combined the stress-based and the fracture-mechanics-based failure criteria, was presented and proved to be suitable for 
graphite materials [13]. In the failure model, damage initiates when the stress-based criterion is first satisfied, and subsequent crack formation and propagation is controlled by a softening interfacial constitutive law, which is essentially a cohesive crack model (CCM). The CCM is based on the Dudgale-Barenblatt [14] cohesive zone approach and has been extended by Hillerborg [15] and Needleman [16] to give a physical explanation of the fracture process. It is often used to simulate crack propagation in quasi-brittle materials [17]. To employ the CCM, a cohesive constitutive law representing the relationship of the cohesive tractions and relative displacements at the interfaces is required. The cohesive constitutive law of graphite, namely the tension softening curve (TSC), has yet to be determined directly from experiments.

In this study, a newly developed incremental displacement collocation method (IDCM) [18], which combines the experimental electronic speckle pattern interferometry (ESPI) technique and the numerical finite element method (FEM), was used to evaluate the TSC of graphites. The parameters of the TSC, including the tensile strength $f_{t}$, the critical crack opening $w_{c}$, and the fracture energy $G_{F}^{\text {TSC }}$, were evaluated using notched beams under bending and compared with values reported elsewhere. Finally, the evaluated TSC in this study was approximated by bilinear, tri-linear and exponential curves, and their effectiveness in modelling the tension 
softening behaviour of graphite was compared. To the authors' knowledge, this represents the first attempt at measuring the TSC of graphite directly.

\section{Theoretical background}

\subsection{The CCM}

The CCM has been widely used to simulate the fracture of quasi-brittle materials. In the CCM, the traction of the surfaces follows a cohesive constitutive law, namely a TSC, which is an important material property for fracture analysis. The TSC, as shown in Fig. 1, is typically represented as a stress-displacement relationship of the form

$$
\sigma=f(w), \quad 0 \leq w \leq w_{c}
$$

where $\sigma$ is the cohesive stress, $w$ is the opening displacement in the cohesive zone, also called the fracture process zone (FPZ) and $f(w)$ represents the TSC to be determined. The cohesive stress is assumed to be equal to the tensile strength $f_{t}$ when $w=0$. As the cohesive crack opening increases, the cohesive stress decreases until the former reaches the critical value, $w_{c}$, at which the cohesive stress disappears.

For numerical analysis, the TSC is often approximated as a linear, bilinear, tri-linear or exponential curve. The curve is typically regulated by both strength-based parameters, such as the tensile strength, and fracture-mechanics-based parameters, 
such as the fracture energy.

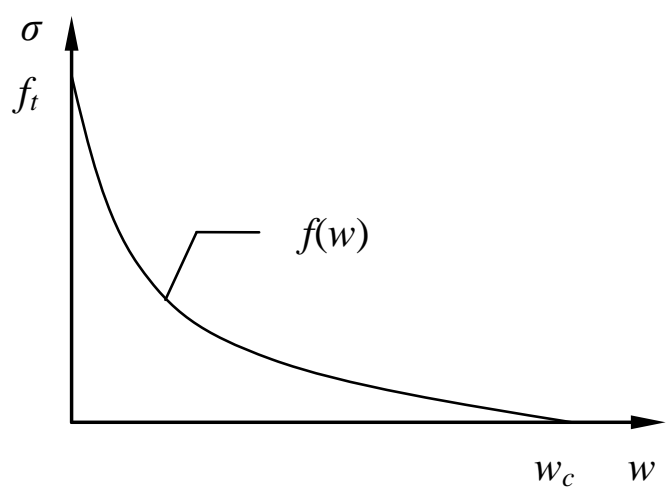

Fig. 1. A cohesive constitutive law.

\subsection{The IDCM}

The IDCM, which utilizes inverse analysis combining a numerical model with experimental measurements, allows the TSC to be determined in a step-by-step manner. In this study, the TSC of graphite was determined using a notched beam under three-point bending (Fig. 2a). At each loading step, only one trial cohesive stress (e.g., $\sigma_{i}$ in Fig. 2b) forming the TSC needs to be evaluated, i.e. the one that gives the correct structural response, as predicted by the finite element model, to the current load. The other preceding cohesive stresses on the TSC, such as $f_{t}$ and $\sigma_{1}$ to $\sigma_{i-1}$, would have been determined in the previous loading steps. The correct cohesive stress is identified by matching the experimental displacements measured from the ESPI technique to the numerical displacements from the finite element analysis at a set of selected collocation points along the FPZ (Fig. 2c). The displacements of the notched beam under three-point bending include the mid-span deflection $\delta$, the notch 
mouth opening displacement (NMOD) and the notch tip opening displacement (NTOD), as described in Fig. 2a. The parameters estimated by the IDCM include the piecewise-linear relationship of the TSC, the critical crack opening $w_{c}$, the tensile strength $f_{t}$ and Young's modulus $E$ of the material.

(a)

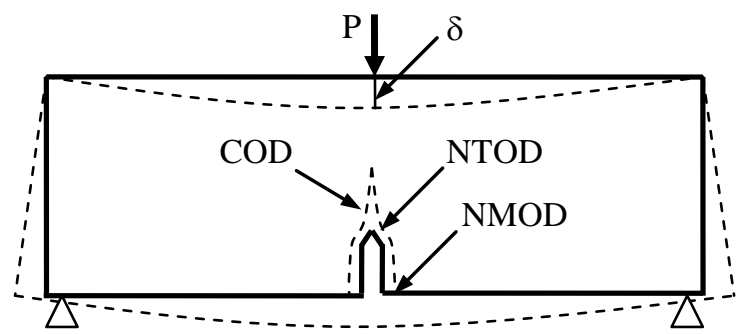

(b)

(c)

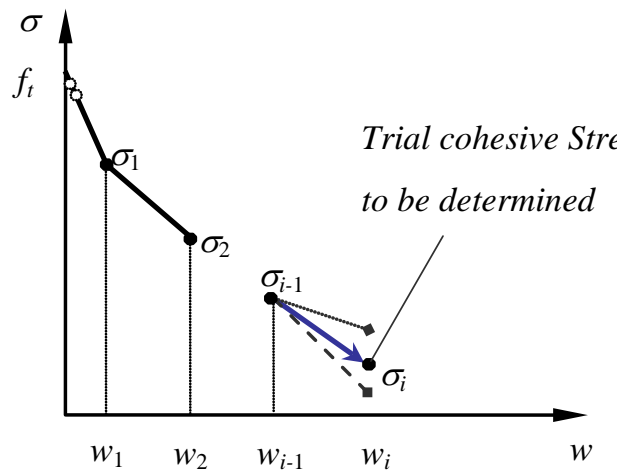
Fitting of $P-\delta$ or $P-N M O D \quad$ Fitting of COD- $i^{\text {th }}$ Step
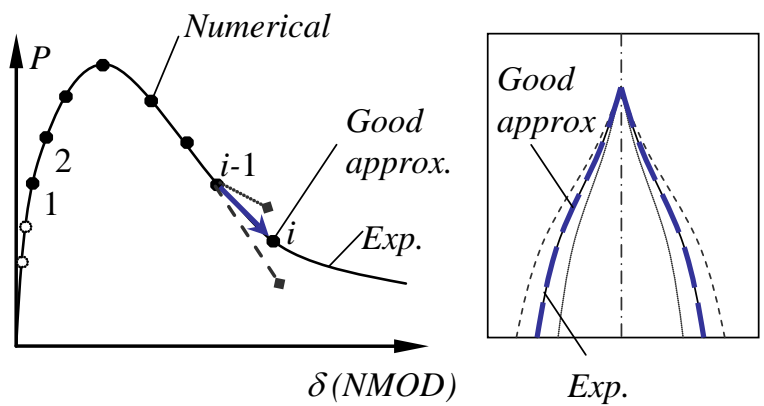

Fig. 2. (a) Displacements of a notched beam under bending; (b) Incremental construction of the TSC; (c) displacement collocation for the estimation of the trial stress;

A flow chart of the computational procedures for the determination of the TSC using the IDCM is presented in Fig. 3. The procedures are briefly described herein.

Step 1: Extract the experimental displacements 
The ESPI technique is used to determine precisely displacements such as the mid-span deflection $\delta$, NMOD, NTOD, the COD profile and the position of the crack front.

Step 2: Estimate the $f_{t}$ and $E$

Using a finite element model, the Young's modulus $E$ can be determined by matching the calculated and measured displacements in the linear elastic region. The model contains interfacial elements, with assigned cohesive stresses, ahead of the notch tip to simulate the FPZ. The $E$ value mainly controls the calculated displacements at the early loading stages when the effects of the cohesive stress are small.

Once the $E$ value is estimated, $f_{t}$ can be determined by satisfying two requirements: 1 ) the maximum calculated stress $\sigma_{\max }$ in the problem domain should be less than or equal to the $f_{t}$ assumed and there should be no abrupt changes or jumps in the stress profile, and 2) a positive COD within the FPZ should be ensured.

It should be noted that, at the early loading stages, the calculated displacements are not very sensitive to variation of the tensile strength; thus, the tensile strength estimated by the inverse analysis might exhibit a variation of approximately $10 \%$ to the mean value. Despite the discrepancy, variations in the fracture energy are extremely small. Therefore, such a discrepancy in the tensile strength would only have a small influence on the overall fracture behaviour of the graphite. 
Step 3: Determine the length of the FPZ

From the COD profile, the crack front and the crack rear (e.g., the initial notch tip) can be recognized, thus length of the FPZ can be identified. In the FPZ, cohesive stresses will be assigned to the interfacial elements along the crack line.

Step 4: Calculate the cohesive stress $\sigma$ in the FPZ

From the COD profile, the crack opening $w(y)$ at various interfacial nodes in the FPZ of the finite element model can be determined. The $y$ coordinate is defined along the crack line with the origin at the notch mouth. At the $i^{\text {th }}$ loading step, as shown in Fig. 2a, all of the nodal points on the TSC in the previous $i-1$ loading steps would have been defined; only the last one, $\left(w_{i}, \sigma_{i}\right)$, needs to be determined using the IDCM. Thus, the cohesive stresses at all the interfacial nodes with $w$ equal to or less than $w_{\mathrm{i}-1}$ can be established. As the TSC must be a descending function, the unknown stress $\sigma_{i}$ should satisfy the following requirement:

$$
\sigma_{i} \leq \sigma_{i-1}
$$

where $\sigma_{i-1}$ is the cohesive stress determined at the $i-1^{\text {th }}$ loading step. For $i=1, \sigma_{0}$ is equal to $f_{t}$.

By linear interpolation, the nodal cohesive stress $\sigma(y)$ at the $j^{\text {th }}$ segment of the TSC can be expressed in terms of the crack opening by

$$
\sigma(y)=\sigma_{j-1}+\frac{\sigma_{j}-\sigma_{j-1}}{w_{j}-w_{j-1}}\left(w(y)-w_{j-1}\right)
$$


where $w(y)$ is the crack opening of the node considered; $\left(w_{j-1}, \sigma_{j-1}\right)$ and $\left(w_{j}, \sigma_{j}\right)$ are the end coordinates of the $j^{\text {th }}$ line segment within which $(w(y), \sigma(y))$ lie; and $j=1,2 \ldots i$. By assigning certain trial values for $\sigma_{i}$, that satisfy Equation (2) and using Equation (3), all of the nodal stresses along the FPZ can be obtained.

Step 5: Input the nodal stress $\sigma(y)$ into the FEM and compute the numerical displacements at the collocation points

The nodal cohesive stress $\sigma_{i}$ is selected only when two additional requirements, the displacement and stress requirements, are satisfied as follows.

The displacement requirement is

$$
\left|d_{n}-d_{e}\right|<\text { Tolerance }
$$

where $d_{n}$ and $d_{e}$ represent the calculated and measured displacements, respectively, in terms of $\delta$, NMOD and NTOD.

For the stress requirements, the calculated stresses in the problem domain should not be greater than $f_{t}$, and the numerical stress profile in the FPZ should be a smooth curve. Prior to the formation of a fully developed cohesive crack, all nodal cohesive stresses should be positive and higher than zero.

Step 6: Proceed to the next loading step and repeat Steps 3 to 5 until the crack opening at the initial notch tip reaches $w_{c}$ and $\sigma_{i}=0$. 


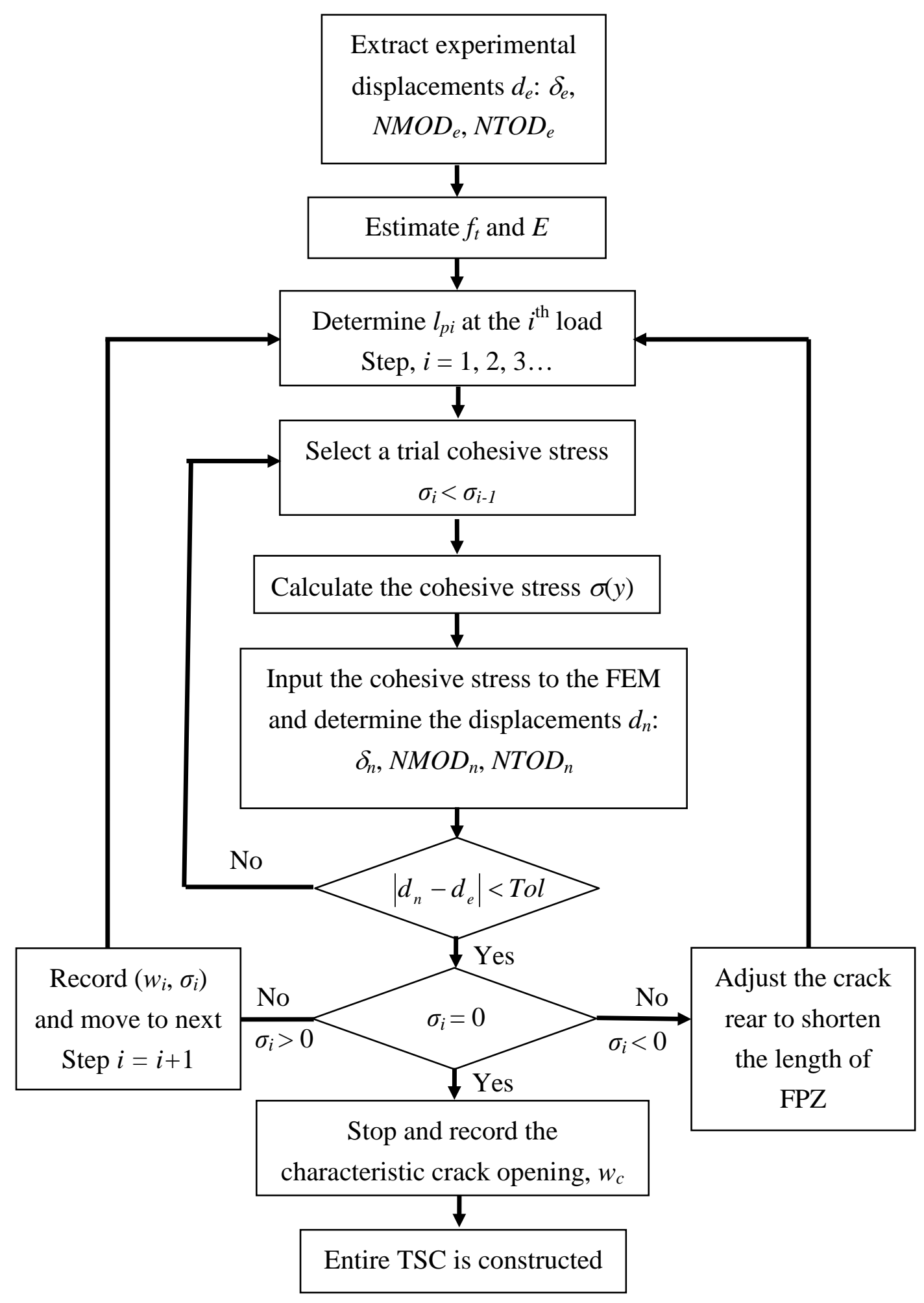

Fig. 3. Flowchart showing the IDCM for the evaluation of the TSC. 


\section{Experimental work}

\subsection{Specimens and experimental setup}

Three-point bend tests on centre-notched beams were conducted to study the fracture properties of the isotropic IG11 graphite (IG11 Series, Toyo Tanso) and a graphite (NG-CT-01 Series) produced in China. The material properties of the graphites are shown in Table 1. Both IG11 and NG-CT-01 use a small grain size and are both manufactured by isostatic pressing. They therefore exhibit similar mechanical and physical properties, as well as near isotropy, as shown in Table 1. Fig. 4 shows scanning electron microscope (SEM) images $(\times 500$ magnification $)$ of polished surfaces of the two graphites. The smaller grain size (Table 1) and better infiltration of the binder of IG11 can be seen.
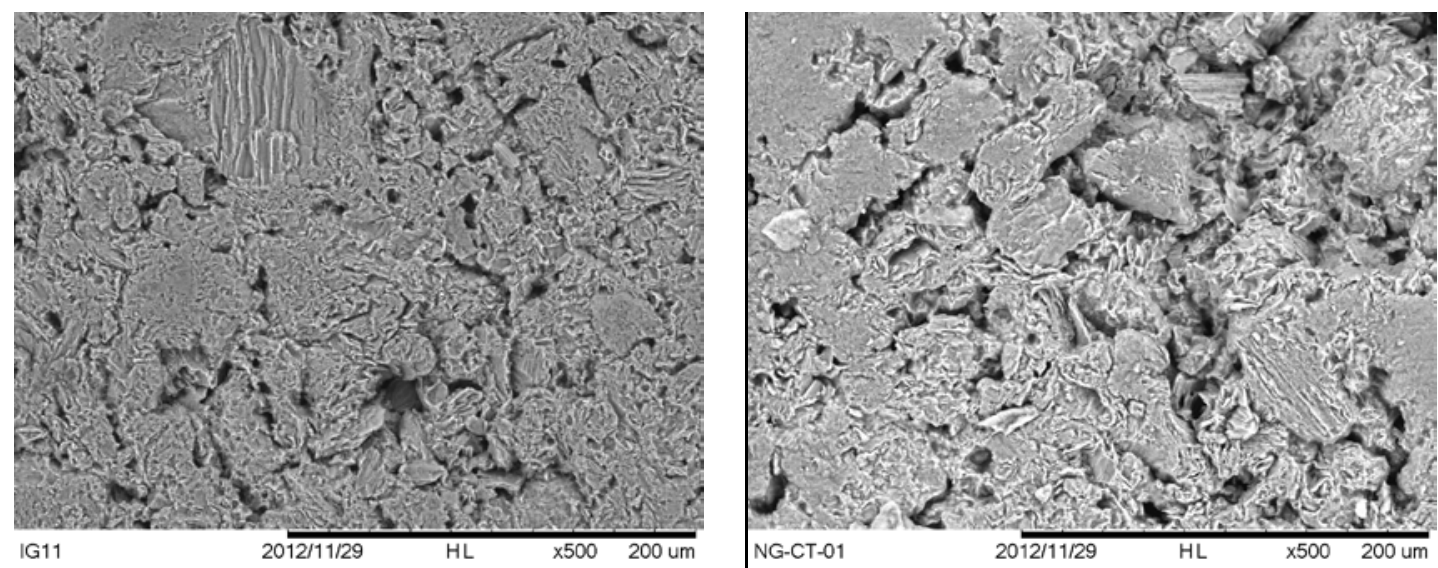

Fig. 4. SEM images of polished surfaces of IG11 (left) and NG-CT-01 (right).

For each series, five beams were prepared. The dimensions $(L \times b \times t)$ of the beams 
were $220 \times 50 \times 25 \mathrm{~mm}^{3}$ and the span was $200 \mathrm{~mm}$. The densities of the beam specimens are shown in Table 2. Independent measurement of the beams' density confirmed the slightly higher value of NG-CT-01. A centre notch was created for each beam by a saw cut. The notch depth was $20 \mathrm{~mm}$ and the notch width was approximately $0.5 \mathrm{~mm}$.

Table 1 Reported mechanical and physical properties of IG11 and NG-CT-01.

\begin{tabular}{cccc}
\hline Property & Units & IG11 & NG-CT-01 \\
\hline Grain size & $\mu \mathrm{m}$ & 20 & 25 \\
Bulk density & $\mathrm{g} / \mathrm{cm}^{3}$ & 1.77 & 1.85 \\
Poisson's ratio & - & 0.14 & 0.14 \\
Hardness & $\mathrm{HSD}$ & 51 & 50 \\
Tensile strength & $\mathrm{MPa}$ & 25 & 24 \\
Flexural strength & $\mathrm{MPa}$ & 39 & 32 \\
Compressive strength & $\mathrm{MPa}$ & 78 & 76 \\
Young's modulus & $\mathrm{GPa}$ & 10 & 10 \\
Coefficient of thermal & $10^{-6} / \mathrm{K}$ & 4.5 & 4.0 \\
expansion & & & 1.1 \\
Coefficient of thermal & - & 1.1 & \\
expansion & & & \\
anisotropy ratio & & & \\
$\left(\alpha_{\text {against grain }} / \alpha_{\text {with grain }}\right)$ & & &
\end{tabular}

Three-point bend tests were carried out using an MTS bend fixture. The experimental setup is shown in Fig. 5. In each test, a jack was moved upward to apply load to the beam using displacement control with a loading rate of $0.01 \mathrm{~mm} / \mathrm{min}$. As notched beams were used in the test, the main crack initiated from the notch tip and propagated along the notch plane direction. Crack growth was well controlled by a 
closed-loop servo hydraulic control system. Approximately 15 min were required to reach the peak load. The NMOD was measured by a clip gauge at the notch mouth, as shown in Fig. $\quad 5 b$. The complete load-deflection $(P-\delta)$ and load-NMOD (P-NMOD) curves were recorded by a data logger.

Table 2 Density of the graphite specimens tested.

\begin{tabular}{cccc}
\hline Specimen No. & $\begin{array}{c}\text { Bulk density } \\
\left(\mathrm{g} / \mathrm{cm}^{3}\right)\end{array}$ & Specimen No. & $\begin{array}{c}\text { Bulk density } \\
\left(\mathrm{g} / \mathrm{cm}^{3}\right)\end{array}$ \\
\hline IG11-1 & 1.78 & NG-CT-01-1 & 1.83 \\
IG11-2 & 1.78 & NG-CT-01-2 & 1.82 \\
IG11-3 & 1.79 & NG-CT-01-3 & 1.83 \\
IG11-4 & 1.77 & NG-CT-01-4 & 1.83 \\
IG11-5 & 1.78 & NG-CT-01-5 & 1.83 \\
\hline
\end{tabular}

A three-dimensional ESPI system, Q300 produced by Dantec-Ettemeyer, was used to measure the surface deformation at the mid-span of the beams. The technical specifications of the Q300 system are listed in Table 3. In the current study, the measuring area was approximately 70 (horizontal) $\times 60$ (vertical) $\mathrm{mm}^{2}$. The measurement sensitivity of the ESPI system depends on the illumination arm, the object distance and the laser wavelength. With a longer illumination arm and a shorter object distance, the measurement sensitivity will be higher. A displacement resolution of $0.2 \mu \mathrm{m}$ was achieved with the described test setup. 
(a)
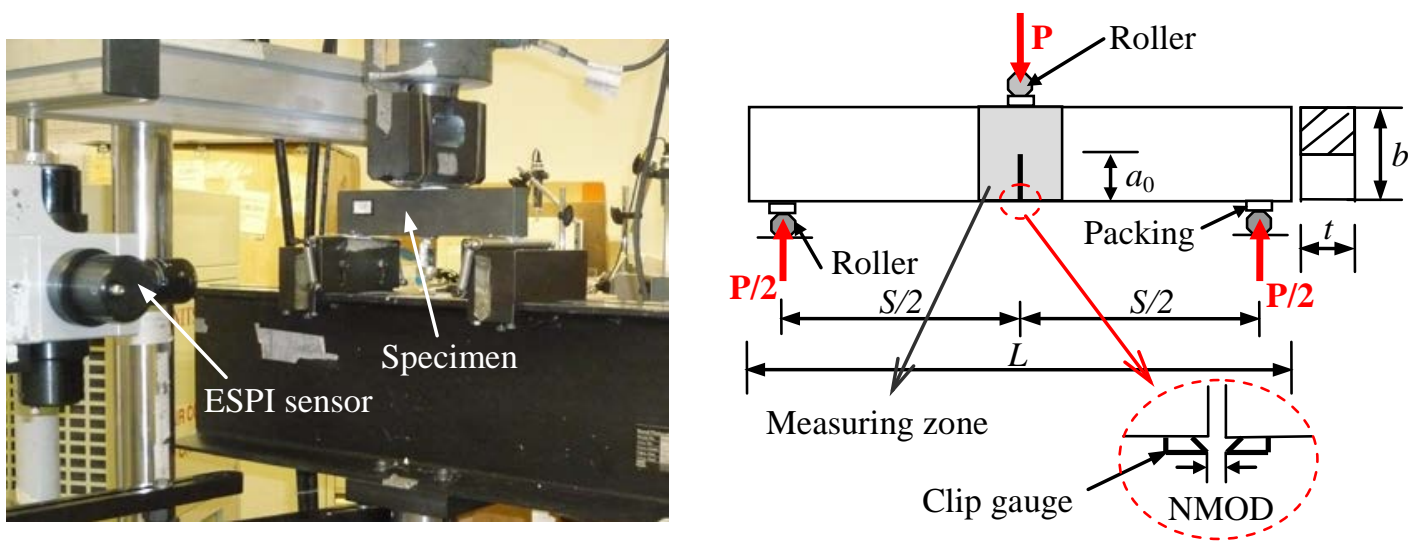

(c)

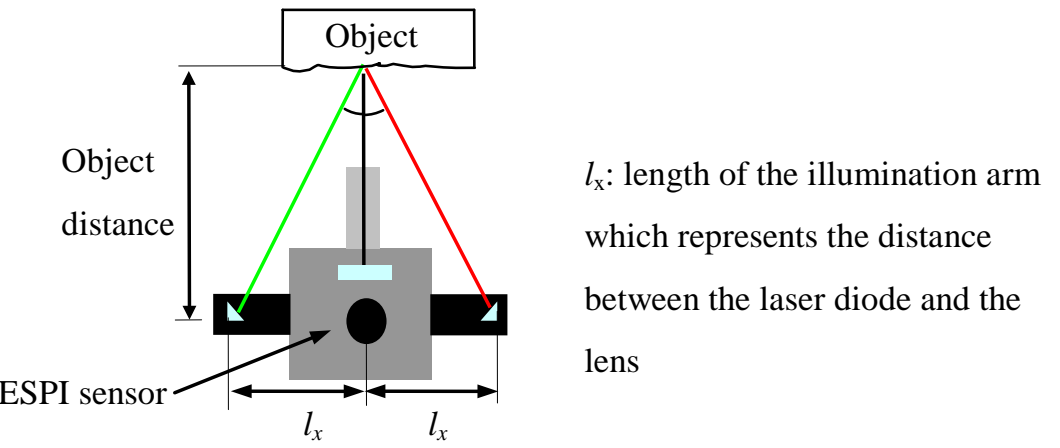

Fig. 5. (a) Experimental setup of three-point bend test; (b) schema of the experimental setup; (c) schema of in-plane ESPI measurement.

Table 3 Technical specifications of the Q300 system.

\begin{tabular}{ll}
\hline Displacement accuracy & $0.05-1 \mu$ m adjustable \\
CCD-resolution & 1392 (horizontal) $\times 1040$ (vertical) pixels \\
Measuring range & Adjustable, $10-100 \mu$ m per step depending on measuring direction \\
Measuring area & Up to $200 \times 300 \mathrm{~mm}^{2}$ with built in illumination \\
Working distance & Variable, $0.2 \ldots 1.0 \mathrm{~m}$ \\
Laser (built in) & Diode, $2 \times 75 \mathrm{~mW}, \lambda=785 \mathrm{~nm}$ \\
\hline
\end{tabular}

At each loading step, the speckle pattern on the measured surface was captured by an

ESPI sensor. The post-processing software ISTRA [19] was used to convert raw ESPI data into full-field displacement data. 


\subsection{Load-displacement curves}

The complete $P-\delta$ and $P-N M O D$ curves of the IG11 and the NG-CT-01 series are shown in Fig. 6 and Fig. 7, respectively. Non-catastrophic fracture was observed for both graphites, which indicated quasi-brittle fracture behaviours.
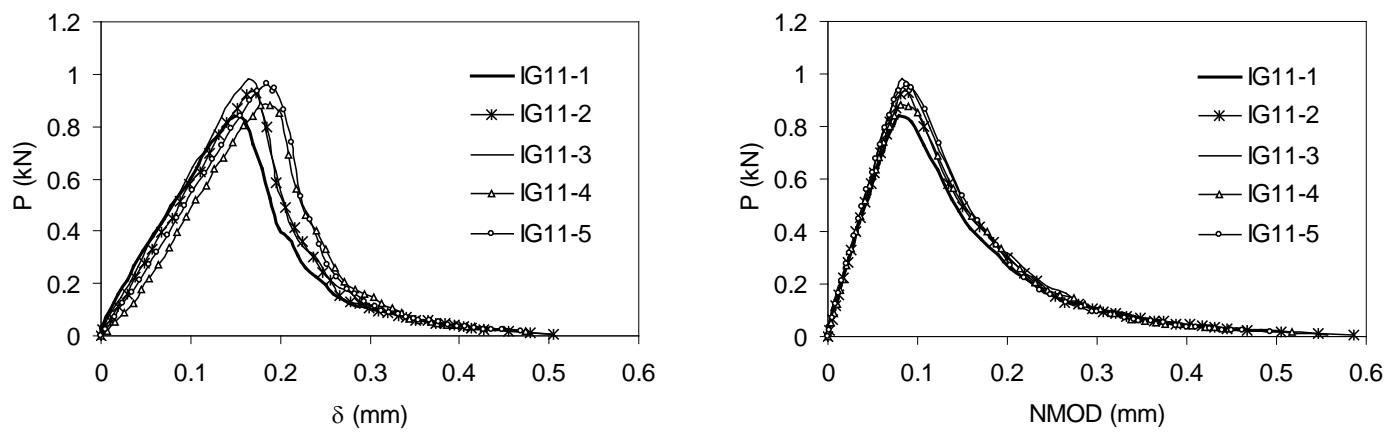

Fig. 6. $P-\delta$ and $P-N M O D$ curves of IG11 series.
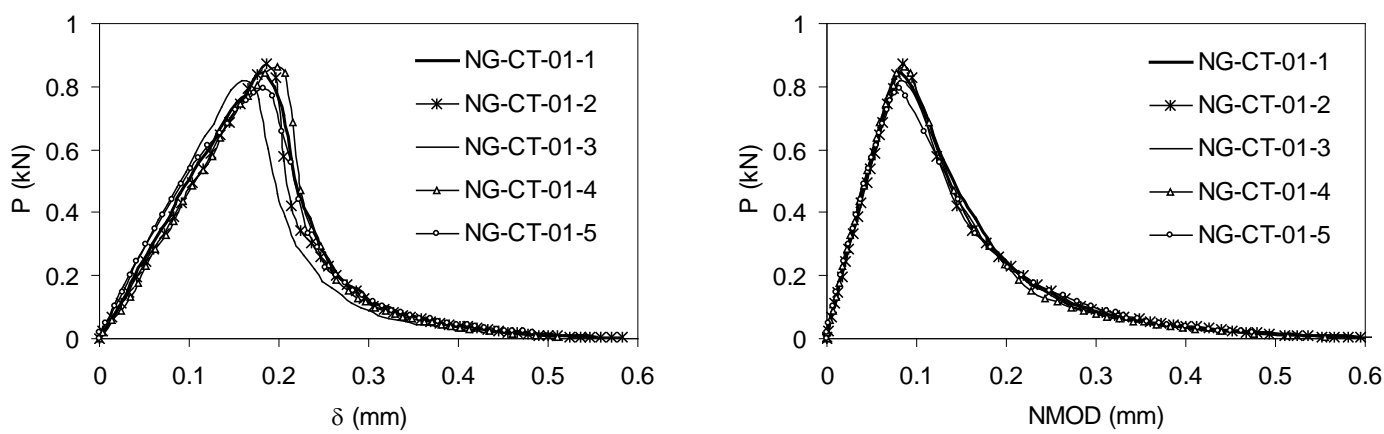

Fig. 7. $P-\delta$ and $P$-NMOD curves of NG-CT-01 series.

Before reaching the peak load, the beams deformed almost linearly as the load increased. The plateau region at the peak was very short and the load beyond it dropped quickly, which indicated that the graphites had little nonlinear deformation in the pre-peak region and their fracture was more brittle than other quasi-brittle 
materials, such as concrete and mortar. The NG-CT-01 graphite showed more brittleness and a lower flexural strength than the IG11 graphite. Fig. 8 shows SEM pictures of the fracture surfaces $(\times 500$ magnification) of the two graphites, with that of NG-CT-01 showing a coarser, more granular appearance.

From Fig. 6 and Fig. 7, it can be observed that the variations in the P-NMOD curves were smaller than those in the $P-\delta$ curves for both the IG11 and the NG-CT-01 series; thus, the $P-N M O D$ curves were generally more suitable for inverse analyses.
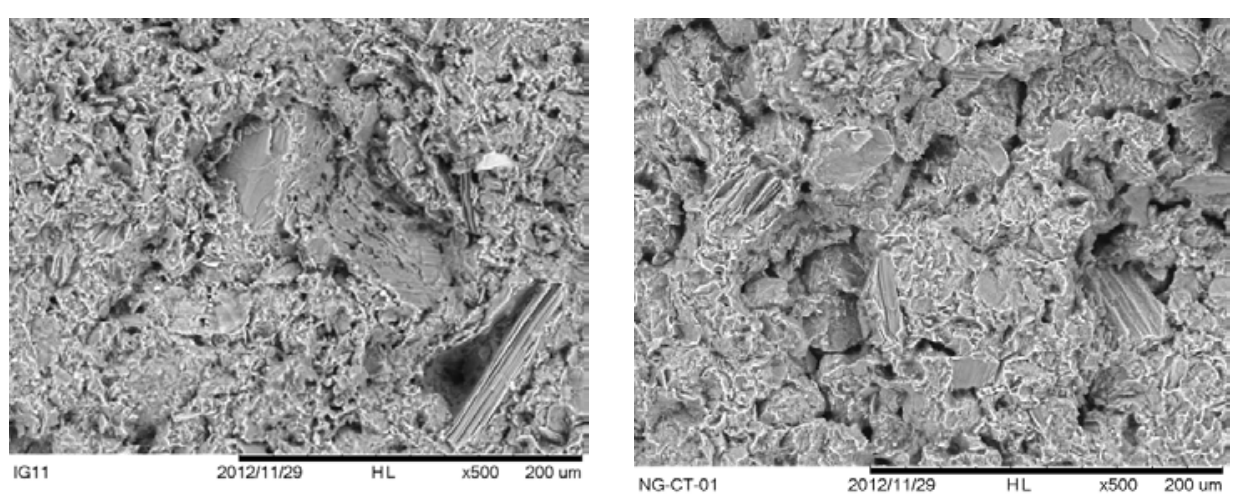

Fig. 8. SEM images of fracture surfaces of IG11 (left) and NG-CT-01 (right).

\subsection{Crack evolution}

As the damage evolution and crack formation for both types of nuclear graphite (IG11 and NG-CT-01) were quite similar, only those for IG11 are presented herein. Fig. 9 shows a typical $P$-NMOD curve from Specimen IG11-1. The main crack was initiated from the initial notch tip and propagated approximately along the notch line. 


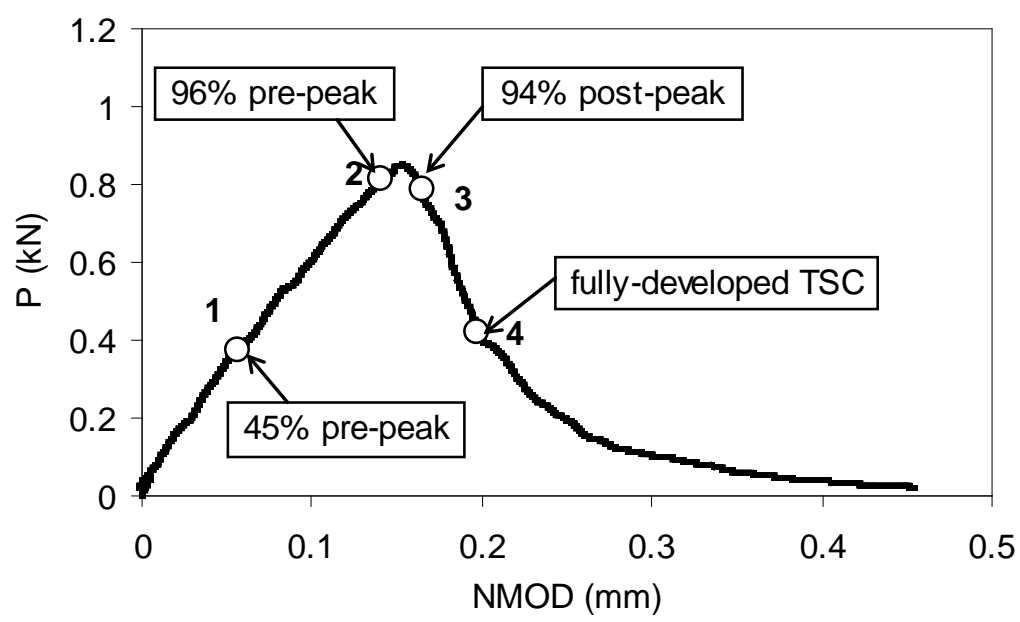

Fig. 9. Four loading stages to be analyzed.

Among all the loading steps selected to derive the TSC, four critical loading steps are depicted in Fig. 9. The interference fringe patterns and wrapped phase maps of the mid-span surface of the beam at the four critical loading steps are shown in Fig. 10. The fringes represent contours of the displacement in the $x$ direction. All the points on one fringe have the same displacement and the difference in displacements between two adjacent fringes is about $2 \mu \mathrm{m}$. A wrapped phase map contains the phase difference of the surface before and after the deformation and may jump by $2 \pi$ from one point to the next. An unwrapped phase map, which relates to the real object deformation, is obtained from the wrapped phase map using a phase-shifting process to eliminate the jumps.

It can be observed from the fringes and phase maps that as the load increased, the two sides of the beam adjacent to the crack deformed almost symmetrically. The cohesive 
crack can be identified from the discontinuity of the fringes and phase maps. The crack tip is recognised as the region with a rapid change of fringes. At the early loading stages (e.g. pre-peak $P<45 \%$ of the peak load), the crack propagated slightly. At the plateau region of the peak load, a considerable amount of strain energy had accumulated. Then, upon further beam bending, the energy was released quickly with rapid crack propagation.

Using the software ISTRA [19], the surface displacement fields were evaluated from the fringe data. The COD profiles at the four loading stages are presented in Fig. 11. It can be observed that the COD profile did not vary linearly as previously assumed [20]. Hence, nonlinear assumptions are more appropriate for modelling the COD profile, especially in the FPZ.

As shown in the figure, at the pre-peak load levels of $45 \%$ and $96 \%$ of the peak load, the cohesive crack lengths were approximately $1 \mathrm{~mm}$ and $4 \mathrm{~mm}$, respectively. After a short plateau, the load started to drop. At the post-peak load level of $94 \%$ of the peak load, the crack length was approximately $7 \mathrm{~mm}$. When a fully developed FPZ was formed, the cohesive crack length reached its maximum value of approximately 15 $\mathrm{mm}$. 

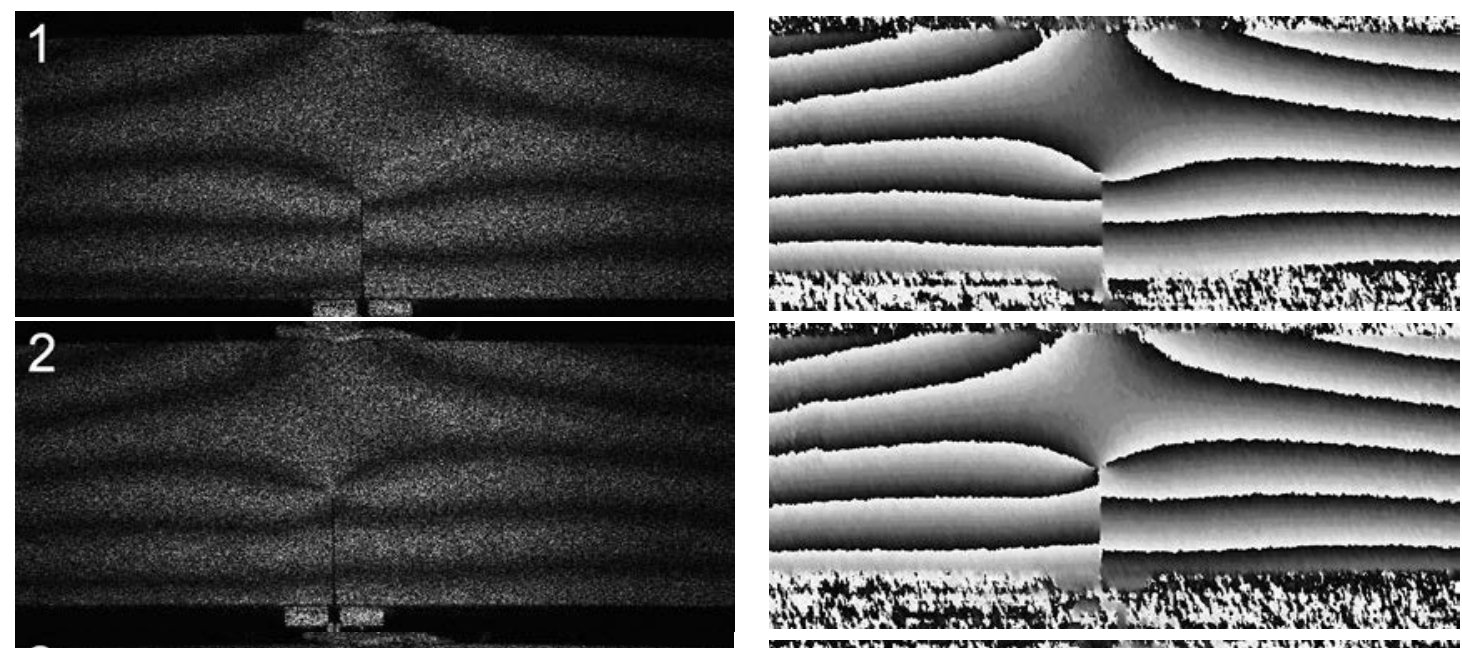

Ding 4t:

3

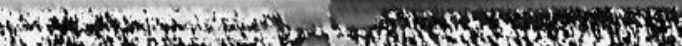

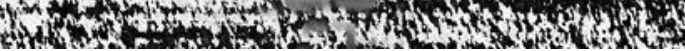

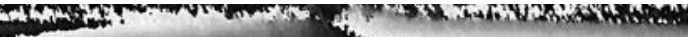

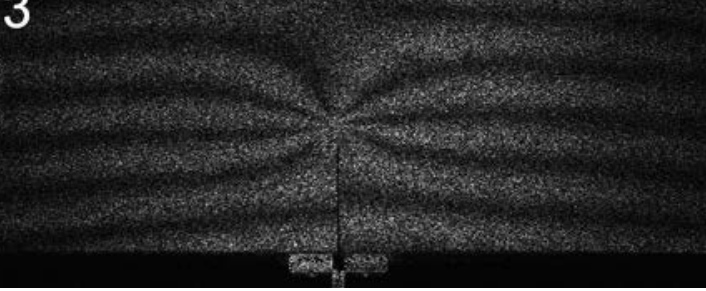

4

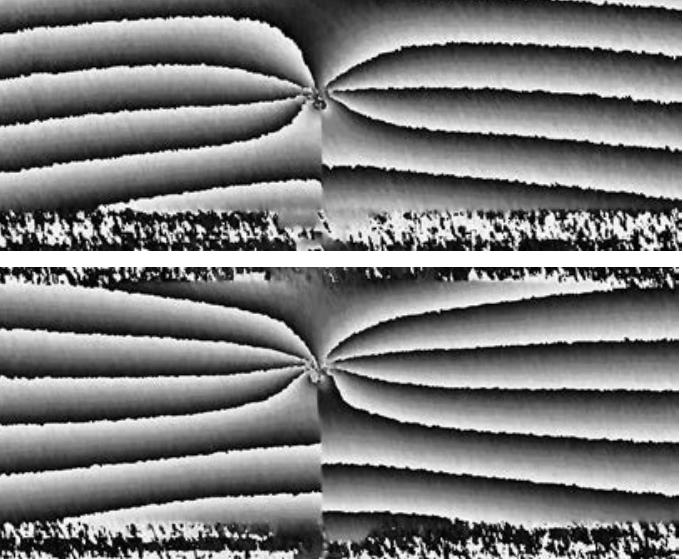

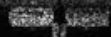

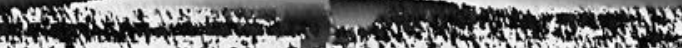

Fig. 10. Interference fringes and wrapped phase maps at the four loading stages.

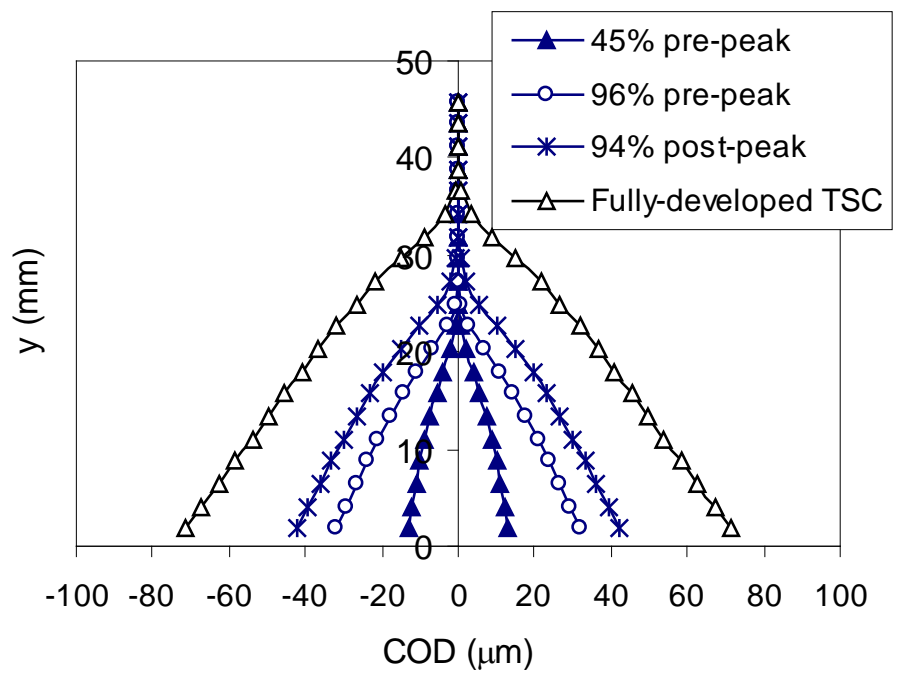

Fig. 11. COD profiles at the four loading stages. 


\subsection{Mode-I fracture toughness and fracture energy}

The Mode-I fracture toughness $K_{I C}$ was calculated from the peak failure load using the following expression [21]:

$$
K_{I C}=\frac{3 Y}{2} \frac{P S}{b^{2} t}
$$

where $b$ and $t$ are the specimen depth and width, respectively, $S$ is the span, and $P$ is the peak fracture load. $Y$ is a geometrical factor. For an edge crack in a three-point bending test, it is given by

$$
Y=\frac{\sqrt{a_{0}}\left(1.99-\frac{a_{0}}{b}\left(1-\frac{a_{0}}{b}\right)\left(2.15-3.93 \frac{a_{0}}{b}+2.7\left(\frac{a_{0}}{b}\right)^{2}\right)\right)}{\left(1+2 \frac{a_{0}}{b}\right)\left(1-\frac{a_{0}}{b}\right)^{\frac{3}{2}}}
$$

where $a_{0}$ is the initial crack depth. For stable crack growth in the notched samples, all of the work from the testing machine is used to create the new crack surfaces rather than to provide kinetic energy to the sample [22-24]; thus, the work of fracture can be obtained from the area under the load-deflection curve. According to the International Union of Laboratories and Experts in Construction Materials Systems and Structures [25], the averaged fracture energy can be obtained by the work-of-fracture method and can be calculated from the entire load-deflection curve by

$$
G_{F}^{P-\delta}=\frac{A_{0}}{\left(b-a_{0}\right) t}
$$

where $A_{0}$ is the area under the load-deflection curve.

The values of the peak load $P_{c}$, the displacements at the peak load (including $\delta_{c}$, 
$N M O D_{c}, N T O D_{c}$ ), the fracture toughness and the fracture energy of each specimen are listed in Tables 4 and 5. From the tables, it can be found that the displacements $\left(\delta_{c}\right.$, $N M O D_{c}, N T O D_{c}$ ) of the two graphite series are quite consistent. The mean values of the fracture toughness $K_{I C}$ for the IG11 and the NG-CT-01 series are $1.30 \pm 0.07$ $\mathrm{MPa} \cdot \mathrm{m}^{1 / 2}$ and $1.21 \pm 0.12 \mathrm{MPa} \cdot \mathrm{m}^{1 / 2}$, respectively. The values are similar to the plateau toughness of $1.2 \mathrm{MPa} \cdot \mathrm{m}^{1 / 2}$ for the IG11 graphite, obtained by Sakai et al. [26] using the compact tensile specimens, and the values of $1.0-1.2 \mathrm{MPa} \cdot \mathrm{m}^{1 / 2}$ for IG110 (Toyo Tanso), obtained by Fazluddin [27] using optical measurements in three-point bending and compact tension tests.

The peak load $P_{c}$, the fracture toughness $K_{I C}$ and the fracture energy $G_{F}$ of the IG11 series are slightly higher than those of the NG-CT-01 series.

Due to the formation of the FPZ, the fracture parameters of graphite can vary with the length of the propagating crack $(\Delta a)$. To examine this variation, the K-curves [28] of IG11 and NG-CT-01 were constructed using Equations (5) and (6) and the increasing crack length determined by ESPI.

The shape of the K-curves for both IG11 and NG-CT-01 (Fig. 12) is similar to the results by Allard et al. [28]. From the figure, it can be observed that the fracture toughness increases quickly during the initial loading due to the development of the FPZ. There is a short plateau region when the crack length is between 5 and $10 \mathrm{~mm}$. 
After the plateau region, the fracture toughness decreases slowly due to the edge effect [28].

Table 4 Experimental results of IG11graphite.

\begin{tabular}{ccccccc}
\hline Specimen No. & $\begin{array}{c}P_{c} \\
(\mathrm{~N})\end{array}$ & $\begin{array}{c}\delta_{c} \\
(\mathrm{~mm})\end{array}$ & $\begin{array}{c}N M O D_{c} \\
(\mathrm{~mm})\end{array}$ & $\begin{array}{c}N T O D_{c} \\
(\mathrm{~mm})\end{array}$ & $\begin{array}{c}K_{I C} \\
\left(\mathrm{MPa} \cdot \mathrm{m}^{1 / 2}\right)\end{array}$ & $\begin{array}{c}G_{F}{ }^{P-\delta} \\
(\mathrm{N} / \mathrm{m})\end{array}$ \\
\hline IG11-1 & 851 & 0.180 & 0.090 & 0.014 & 1.21 & 181.3 \\
IG11-2 & 934 & 0.172 & 0.090 & 0.012 & 1.32 & 188.6 \\
IG11-3 & 983 & 0.171 & 0.092 & 0.013 & 1.39 & 198.1 \\
IG11-4 & 890 & 0.188 & 0.091 & 0.007 & 1.26 & 189.2 \\
IG11-5 & 922 & 0.188 & 0.091 & 0.010 & 1.31 & 203.2 \\
Mean & 914 & 0.180 & 0.091 & 0.011 & 1.30 & 192.1 \\
Std dev. & 49 & 0.008 & 0.001 & 0.003 & 0.07 & 8.6 \\
\hline
\end{tabular}

Table 5 Experimental results of NG-CT-01 graphite.

\begin{tabular}{ccccccc}
\hline Specimen No. & $\begin{array}{c}P_{c} \\
(\mathrm{~N})\end{array}$ & $\begin{array}{c}\delta_{c} \\
(\mathrm{~mm})\end{array}$ & $\begin{array}{c}\text { NMOD } \\
(\mathrm{mm})\end{array}$ & $\begin{array}{c}\text { NTOD } \\
(\mathrm{mm})\end{array}$ & $\begin{array}{c}K_{I C} \\
\left(\mathrm{MPa} \cdot \mathrm{m}^{1 / 2}\right)\end{array}$ & $\begin{array}{c}G_{F}^{P-\delta} \\
(\mathrm{N} / \mathrm{m})\end{array}$ \\
\hline NG-CT-01-1 & 845 & 0.181 & 0.09 & 0.013 & 1.20 & 186.7 \\
NG-CT-01-2 & 871 & 0.189 & 0.091 & 0.01 & 1.24 & 180.0 \\
NG-CT-01-3 & 821 & 0.165 & 0.091 & 0.013 & 1.16 & 167.6 \\
NG-CT-01-4 & 762 & 0.183 & 0.081 & 0.009 & 1.08 & 182.8 \\
NG-CT-01-5 & 978 & 0.177 & 0.092 & 0.010 & 1.39 & 184.1 \\
Mean & 855 & 0.179 & 0.089 & 0.011 & 1.21 & 180.2 \\
Std dev. & 80 & 0.009 & 0.005 & 0.002 & 0.12 & 7.5 \\
\hline
\end{tabular}




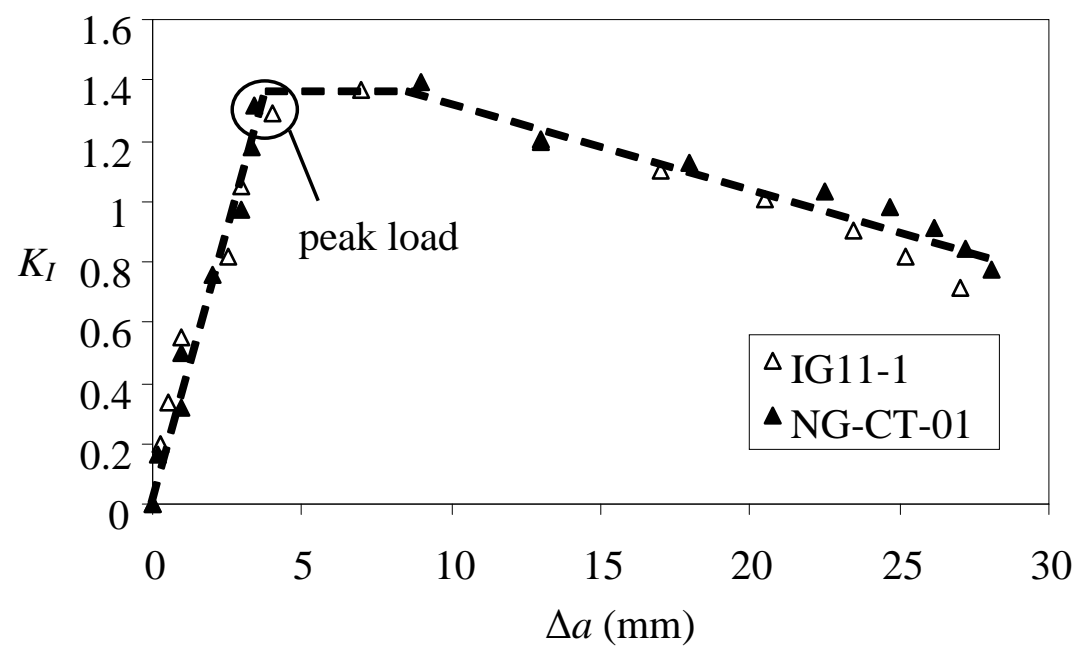

Fig. 12. K-curves for IG11 and NG-CT-01.

\section{Numerical simulation and results}

\subsection{Description of the numerical model}

The three-point bend test was simulated using FEM. Due to the symmetry of the specimen, only half of the beam was analysed. The specimen configuration and finite element meshes are illustrated in Fig. 13. A total of 450 9-node hybrid elements [29] were used in the analysis. The bulk material was assumed to be linear elastic. It has been reported $[30,31]$ that the Poisson's ratio of graphite is within $0.14-0.3$. The Poisson's ratio was found to have little influence on the overall fracture behaviour [27], so a Poisson's ratio of 0.2 was assumed in the current study, the same value as that used in [27]. 


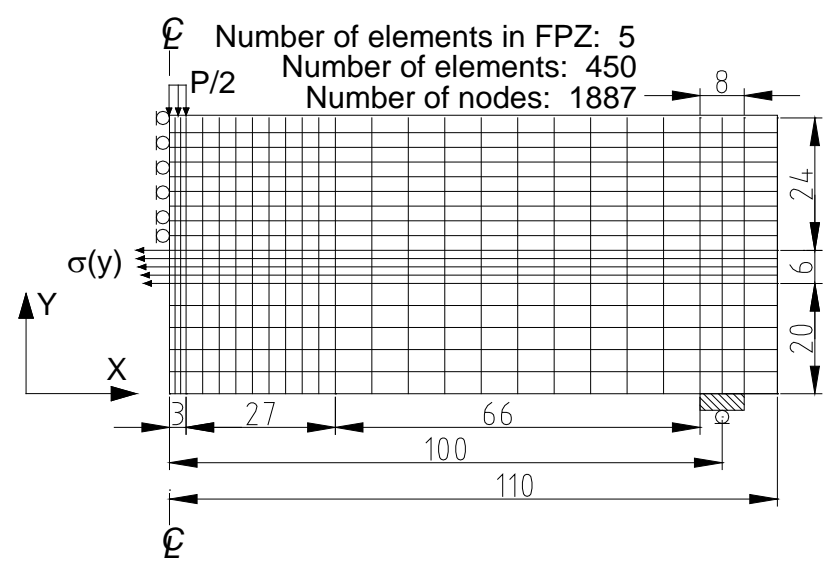

Fig. 13. Specimen configuration and FE meshes (unit: mm).

As shown in Fig. 13, the beam section along the notch was divided into three zones: the initial notch $(y=0-20 \mathrm{~mm})$, the cohesive crack ( $y=20-26 \mathrm{~mm})$ and the linear elastic region $(y=26-50 \mathrm{~mm})$. The calculated cohesive stress $\sigma(y)$ was applied to the cohesive zone to simulate the nonlinear fracture response of the beam. By minimising the discrepancy between the numerical and experimental displacements at the collocation points, the cohesive stress was determined at each loading step to form the TSC.

\subsection{The TSCs of graphite}

By using the IDCM, the TSCs determined for the IG11 and the NG-CT-01 series are presented in Fig. 14. The TSCs can generally be divided into three parts. In the first part, where $w<5 \mu \mathrm{m}$ and $w<3 \mu \mathrm{m}$ for the IG11 and the NG-CT-01 series, respectively, the cohesive stress drops sharply. In the second part, the cohesive stress decreases at a reducing rate with an increase in the crack opening. At the peak load, 
the cohesive stress at the initial notch tip reduces to approximately $4 \mathrm{MPa}$ and 4.6 MPa for the IG11 and the NG-CT-01 series, respectively. In the tail part, the cohesive stress decreases almost linearly with further increases of crack opening.
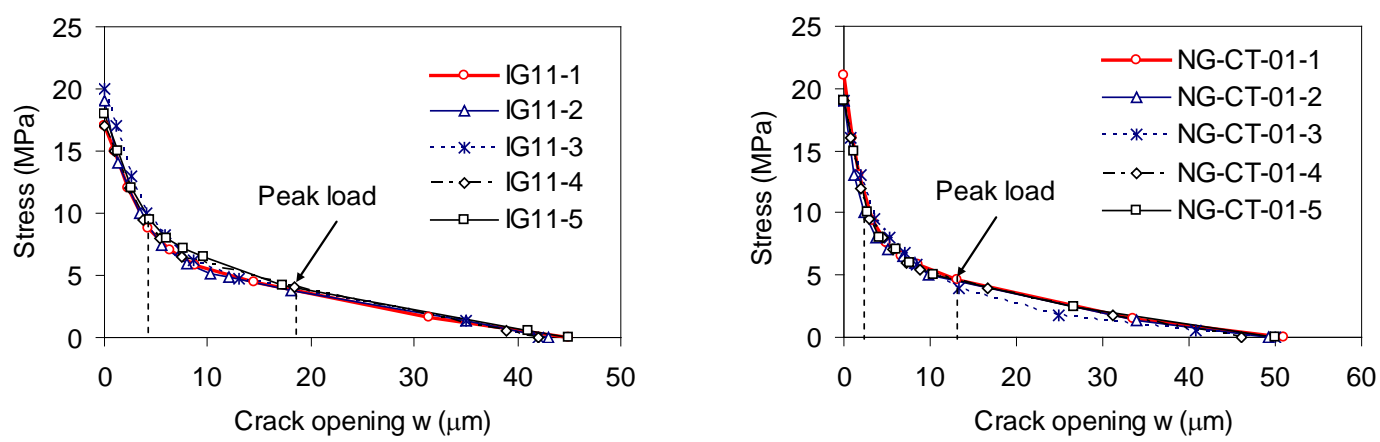

Fig. 14. Calculated TSCs of IG11 and NG-CT-01 series.

The parameters that are used to describe the TSCs are listed in Table 6. The estimated tensile strengths of the IG11 and the NG-CT-01 series are approximately $18.2 \pm 1.3$

MPa and $19.4 \pm 0.9 \mathrm{MPa}$, respectively. The tensile strengths are found to be much lower than the manufacturers' specified tensile strength of 25 MPa shown in Table 1.

Table 6 Fracture parameters estimated from the IDCM.

\begin{tabular}{cccccccccc}
\hline Specimen & $w_{c}$ & $f_{t}$ & $E$ & $G_{F}^{T S C}$ & Specimen & $w_{c}$ & $f_{t}$ & $E$ & $G_{F}^{P-\delta}$ \\
No. & $(\mu \mathrm{m})$ & $(\mathrm{MPa})$ & $(\mathrm{GPa})$ & $(\mathrm{N} / \mathrm{m})$ & No. & $(\mu \mathrm{m})$ & $(\mathrm{MPa})$ & $(\mathrm{GPa})$ & $(\mathrm{N} / \mathrm{m})$ \\
IG11-1 & 45 & 17.0 & 12.5 & 179.0 & NG-CT-01-1 & 51 & 21.0 & 12.0 & 183.5 \\
IG11-2 & 43 & 19.0 & 11.5 & 180.3 & NG-CT-01-2 & 49 & 19.0 & 11.8 & 172.3 \\
IG11-3 & 42 & 20.0 & 12.5 & 191.4 & NG-CT-01-3 & 50 & 19.0 & 12.0 & 164.1 \\
IG11-4 & 42 & 17.0 & 12.0 & 185.2 & NG-CT-01-4 & 46 & 19.0 & 10.0 & 175.1 \\
IG11-5 & 45 & 18.0 & 12.5 & 196.7 & NG-CT-01-5 & 50 & 19.0 & 12.5 & 180.4 \\
Mean & 43.4 & 18.2 & 12.2 & 186.5 & Mean & 49.2 & 19.4 & 11.7 & 175.1 \\
Std dev. & 1.5 & 1.3 & 0.4 & 7.5 & Std dev. & 1.9 & 0.9 & 1.0 & 7.5 \\
\hline
\end{tabular}

The Young's modulus value estimated by the IDCM for the IG11 and NG-CT-01 graphite varies from 10.0 to $12.5 \mathrm{GPa}$, which is quite consistent with the previously 
reported values of 11-12 GPa for Gilsocarbon graphite [30] and $11.6 \pm 0.8 \mathrm{GPa}$ for another isotropic graphite [9]. However, these values are slightly higher than the 9.8 GPa value obtained by Sakai et al. [26] for IG11 graphite.

The critical crack openings for IG11 and NG-CT-01 are found to be $43.4 \mu \mathrm{m}$ and 49.2 $\mu \mathrm{m}$, respectively.

With a fully developed TSC, the fracture energy can be derived from the integral

$$
G_{F}^{T S C}=\int_{0}^{w_{c}} \sigma d w
$$

The fracture energies determined from the $P-\delta$ curve and the TSC were compared and a very good agreement was obtained with differences of less than $4 \%$. The mean fracture energy for the IG11 series and the NG-CT-01 series are $192.1 \pm 8.6 \mathrm{~N} / \mathrm{m}$ and $180.2 \pm 7.5 \mathrm{~N} / \mathrm{m}$, respectively. The values are comparable to the results (150 - 220 N/m for IG-11 graphite) obtained by Sakai et al. [26] and are also consistent with those (180 - $200 \mathrm{~N} / \mathrm{m}$ for IM1-24 graphite) by Ouagne et al. [32].

\subsection{The numerical load-displacement curves}

Using IG11-1 as an example, the displacements of the beam at various post-peak loading steps were calculated by using FEM with the estimated TSC to validate its values. As shown in Fig. 15, before the TSC was fully established, or before the FPZ was fully formed, the calculated displacements (see the solid circles in the figure) 
were compared with the experimental results to calibrate the collocation process. After the entire TSC was estimated the calculated displacements (see the hollow circles in the figure) were used to check its validity. An excellent agreement is observed between the numerical displacements and the experimental displacements over the entire loading process.
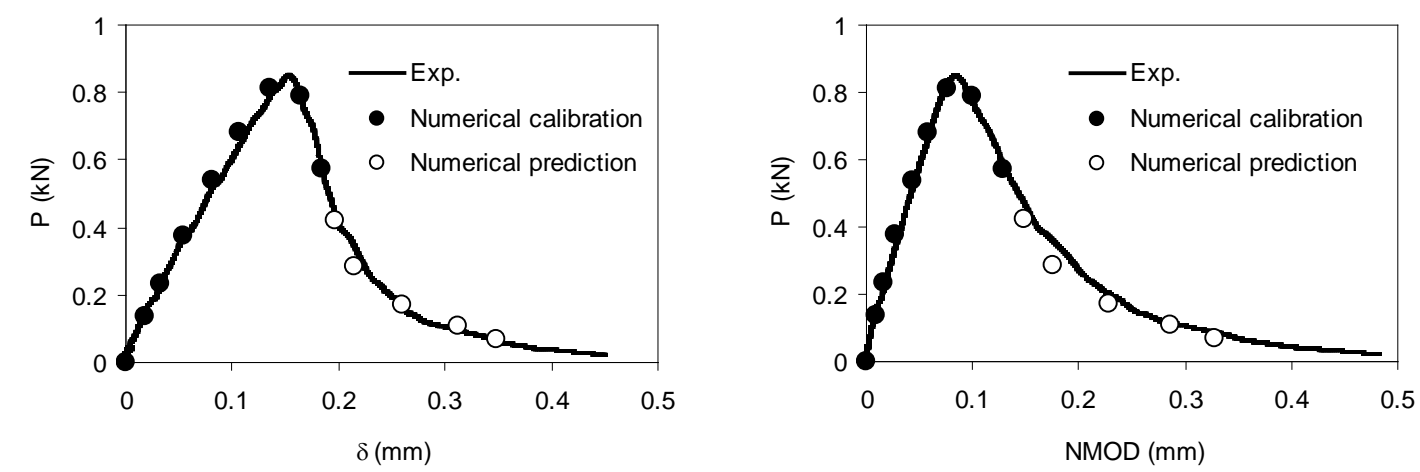

Fig. 15. Numerical $P$ - $\delta$ and $P$-NMOD curves.

\subsection{Parametric analysis of the TSCs}

The bilinear [33], tri-linear [34] and exponential [35] curves are widely used to approximate the TSCs of quasi-brittle materials. To facilitate future simulations of graphite fracture using commercial finite element packages, the TSCs identified in the current study were simplified to the idealised curves using regression analysis. The idealised curves are shown in Fig. 16. The basic parameters used to define the idealised TSC, including the total fracture energy $\left(G_{F}\right)$, the tensile strength $f_{t}$ and the critical crack opening $w_{c}$, were obtained from the inverse analysis. In addition to these parameters, each curve has its own parameters to be determined. 
(a)

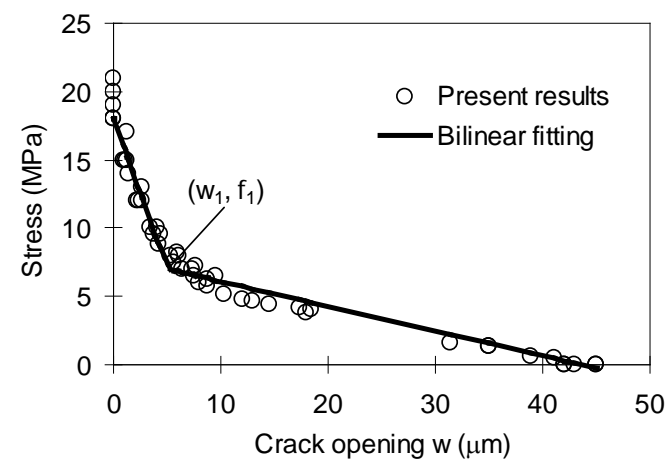

(b)

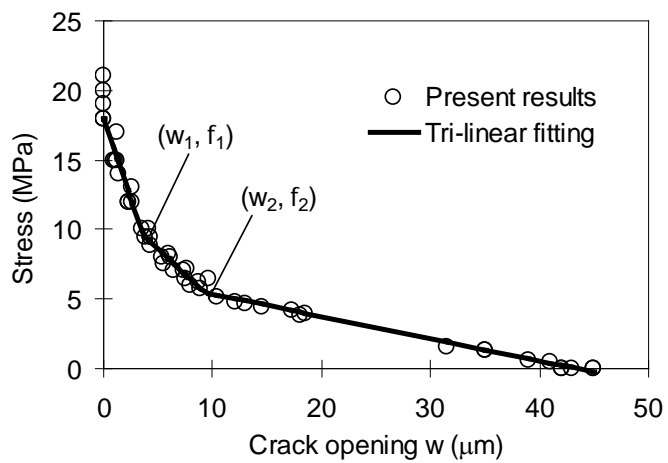

(c)

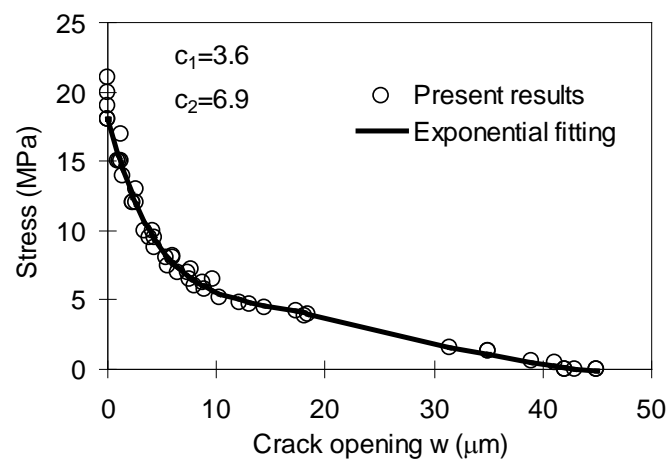

Fig. 16. Approximations of the TSC estimated: (a) bilinear fitting; (b) tri-linear fitting; (c) exponential fitting.

\section{(A) Bilinear curve}

As shown in Fig. 16a, the critical parameter for a bilinear curve is the location of the kink point $\left(w_{1}, f_{1}\right)$.

(B) Tri-linear curve

Referring to Fig. 16b, there are two break points to be determined when using a tri-linear curve to fit the TSC: $\left(w_{1}, f_{1}\right)$ and $\left(w_{2}, f_{2}\right)$.

(C) Exponential curve 
As shown in Fig. 16c, the exponential curve was derived empirically by Hordijk [35].

The function is expressed as

$$
\begin{gathered}
\frac{\sigma}{f_{t}}=\left\{1+\left(c_{1} \frac{w}{w_{c}}\right)^{3}\right\} \exp \left(-c_{2} \frac{w}{w_{c}}\right)-\frac{w}{w_{c}}\left(1+c_{1}^{3}\right) \exp \left(-c_{2}\right) \\
w_{c}=c_{3} \frac{G_{F}}{f_{t}}
\end{gathered}
$$

where $c_{1}, c_{2}$ and $c_{3}$ are the constants to be determined for nuclear graphite.

A complete set of parameters for defining the bilinear, tri-linear and exponential curves is listed in Table 7. All the idealised curves could provide a satisfactory approximation for the TSCs if the initial descent of the TSC was not too sharp. However, when the tensile strength is high and the cohesive stress drops suddenly in the initial region of the TSC, only the tri-linear curve can accurately capture the abrupt change. Thus, the tri-linear curve is the best for fitting the TSC of nuclear graphite.

\begin{tabular}{|c|c|c|c|c|c|c|c|c|c|c|c|}
\hline \multirow{2}{*}{ Series } & \multicolumn{2}{|c|}{$\begin{array}{c}\text { Fracture } \\
\text { parameters }\end{array}$} & \multicolumn{2}{|c|}{$\begin{array}{c}\text { Bilinear } \\
\text { curve }\end{array}$} & \multicolumn{4}{|c|}{ Tri-linear curve } & \multicolumn{3}{|c|}{$\begin{array}{c}\text { Exponential } \\
\text { curve }\end{array}$} \\
\hline & $\begin{array}{c}G_{F} \\
(\mathrm{~N} / \mathrm{m})\end{array}$ & $\begin{array}{c}f_{t} \\
(\mathrm{MPa})\end{array}$ & $\begin{array}{c}w_{1} \\
(\mu \mathrm{m})\end{array}$ & $\begin{array}{c}f_{1} \\
(\mathrm{MPa})\end{array}$ & $\begin{array}{c}w_{1} \\
(\mu \mathrm{m})\end{array}$ & $\begin{array}{c}f_{1} \\
(\mathrm{MPa})\end{array}$ & $\begin{array}{c}w_{2} \\
(\mu \mathrm{m})\end{array}$ & $\begin{array}{c}f_{2} \\
(\mathrm{MPa})\end{array}$ & $c_{1}$ & $c_{2}$ & $c_{3}$ \\
\hline IG11 & 192.1 & 18.2 & 5.1 & 7.0 & 4.7 & 8.3 & 11.1 & 5.0 & 3.6 & 6.9 & 4.1 \\
\hline NG-CT-01 & 180.2 & 19.4 & 3.7 & 6.8 & 2.5 & 9.5 & 10.2 & 4.4 & 3.8 & 7.5 & 5.3 \\
\hline
\end{tabular}

Table 7 Parameters of various idealised TSC curves. 


\subsection{Discussions}

Similar to mortar [18], graphite shows nonlinear and quasi-brittle fracture behaviour due to the formation of a cohesive zone with microcracks. Graphite, however, has higher fracture energy than mortar, and it shows more brittleness as seen from the load-displacement curve as well as the tension softening curve. The post-peak region of the load-displacement curve and the initial part of the tension softening curve of graphite drop more quickly than those of mortar. Besides, the characteristic crack opening for graphite is lower than that of mortar. This may be explained by the smaller grain size of graphite. Rice et al. [36, 37] studied the grain-size dependence of fracture energy in ceramics and indicated that the fracture energy of noncubic materials increased as the grain size decreased. Generally, the smaller the particle size of the material, the more brittle it is. In general, however, the shape of the curves depends on both the mechanical property of the material and the test geometry. It would be much more difficult to obtain stable crack growth and gradual post-peak load reduction with unnotched specimens.

IG11 was shown to have higher fracture strength and fracture toughness than NG-CT-01, which may be due to differences in the bulk density and grain size of the two graphite series. Eto and Growcock [38] pointed out that the mechanical strength of nuclear graphite is significantly influenced by its density. Depending on the 
materials, a $10 \%$ change in the density can cause a variation of approximately $50 \%$ in the mechanical strength. As shown in Table 1, the density of the NG-CT-01 series is approximately $2.5 \%$ higher than that of the IG11 series. However, this does not provide NG-CT-01 with better fracture properties. Instead, the finer grain size and better binder infiltration of IG11 (Fig. 4) appear to be more important in enhancing the material's fracture properties.

Typical values of 24 to $26 \mathrm{MPa}$ were obtained from uniaxial tensile tests for the tensile strength of IG11 [39]. These are much higher than those obtained for the TSC of IG11 and NG-CT-01 in this study. However, Planas et al. [40] found that for a cohesive crack in an edge-notched beam subjected to three-point bending, extremely high longitudinal and transversal tensile stresses co-exist in the cohesive crack. Hence, the material near the cohesive crack tip is actually in a biaxial tension condition. Under such a stress state, the ultimate principal stresses for graphite could be substantially reduced $[39,41]$ when compared with the uniaxial tensile strength, as shown in Fig. 17. This may explain why the tensile strength evaluated by the IDCM for the notched beams is lower than that obtained from the uniaxial tensile tests. In addition, the tensile strength may also be affected by the size effects; i.e. the tensile strength usually decreases with an increase in the specimen size [42]. 
The fracture energy calculated from the $P$ - $\delta$ curve is slightly higher than that from the TSC, which can be explained by the mechanism of energy consumption. The fracture energy derived from the $P$ - $\delta$ curve is based on the assumption that energy absorption takes place only in the FPZ, and all the deformations outside the FPZ are purely elastic [20]. However, a small proportion of the energy might be consumed by friction and the formation of microcracks outside the FPZ; thus, the fracture energy could be slightly overestimated when derived from the $P-\delta$ curve.

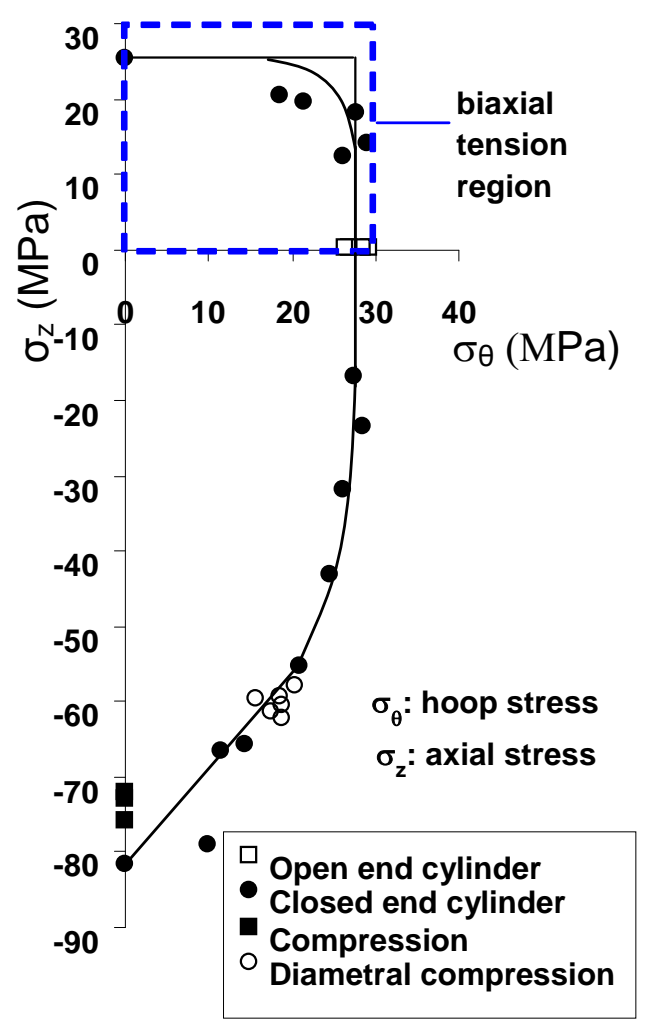

Fig.17. Experimental results of fracture strengths and the specifications of the minimum ultimate strengths of IG11 graphite [39].

The size of the fully formed FPZ for IG11 and NG-CT-01 was estimated to be 15 
mm. This was similar to the reported size for the bridging zone thought to be responsible for the R-curve behaviour of another graphite [22]. Indeed, the formation of the FPZ was shown to be responsible for the similar, K-curve behaviour (Fig. 12) in the two graphites investigated in this study.

It should be noted that the crack front might not be straight and the characteristics of the crack might be affected by the specimen geometry and loading configurations. Hodgkins et al. [12] showed that crack front curvature developed in compact tension specimens with greater thickness (typically $>25 \mathrm{~mm}$ ) and that cracks propagated out of the plane of the notch with decreasing thickness (typically $<20 \mathrm{~mm}$ ). The graphite beam in the present study had a thickness of $25 \mathrm{~mm}$, and major crack deflection from the notch plane was not observed. However, since ESPI could only measure surface displacements, the actual crack front could not be established and the true crack extension/opening might be underestimated.

As mentioned, the mechanical properties of graphite are controlled by its microstructure. When used as a moderator in nuclear reactors, changes in the microstructure and mechanical properties can be caused by neutron irradiation and radiolytic oxidation. Generally, the tensile strength and Young's modulus reduce after extensive irradiation and oxidation. The fracture properties of the graphites investigated in the present study are expected to follow suit. 


\section{Conclusions}

In this study, the fracture properties of two types of nuclear graphite, IG11 and NG-CT-01, were investigated. By using the IDCM, the TSCs and FPZ size of these nuclear graphites were calculated through three-point bend tests on notched graphite beams. The Mode-I fracture toughness $K_{I C}$, the fracture energy $G_{\mathrm{F}}$ and the K-curve behaviour were also determined. The tensile strength of graphite ahead of the notch tip, which was under a biaxial tension condition, was found to be substantially lower than the tensile strength of graphite subjected to uniaxial tension. The Young's moduli and the fracture energies obtained from the IDCM generally agreed with the results from the literature. The TSC obtained was verified through the comparisons of the experimental and numerical load-displacement curves and fracture energies. Finally, the SEM images of the nuclear graphites revealed that the brittleness and fracture behaviours of nuclear graphites were affected by its microstructure.

\section{Acknowledgements}

The work described in this paper was supported by The University of Hong Kong through the Small Project Funding 2012 and funding received from the DOE Office of Nuclear Energy's Nuclear Energy University Programs. 


\section{References}

[1] Gu JL, Leng Y, Gao Y, Liu H, Kang FY, Shen WN. Fracture mechanism of flexible graphite sheets. Carbon 2002;40(12):2169-76.

[2] Burchell TD. A microstructurally based fracture model for nuclear graphite. In: International Atomic Energy Agency (IAEA) specialists meeting on status of graphite development for gas-cooled reactors. Tokai (Japan); 1991.

[3] Burchell TD. A microstructurally based fracture model for nuclear graphite. In: International Atomic Energy Agency (IAEA) specialists meeting on status of graphite development for gas-cooled reactors. Tokai (Japan); 1991.

[4] Lim YS, Chi SH, Cho KY. Change of properties after oxidation of IG-11 graphite by air and CO2 gas. J Nucl Mater 2008;374(1-2):123-8.

[5] Hodgkins A, Marrow TJ, Wootton MR, Moskovic R, Flewitt PEJ. Fracture behaviour of radiolytically oxidised reactor core graphites: a view. Mater Sci Technol Lond 2010;26(8):899-907. [6] Woolley RL. The elasticity of polycrystalline graphite. Philos Mag 1965;11(111):475-83.

[7] Yoda S, Eto M, Oku T. Change in dynamic Youngs modulus of nuclear-grade isotropic graphite during tensile and compressive stressing. $\mathrm{J}$ Nucl Mater 1983;119(2-3):278-83. 
[8] Malmstrom C, Keen R, Green L. Some mechanical properties of graphite at elevated temperatures. J Appl Phys 1951;22:593-600.

[9] Cosculluela A, Farre J. Uniaxial compressive behaviour of an isotropic graphite. J Phys IV France 1997;7(C3):471-6.

[10] Barbieri E, Meo M. A meshless cohesive segments method for crack initiation and propagation in composites. Appl Compos Mater 2011;18(1):45-63.

[11] Nemeth NN, Bratton RL. Statistical models of fracture relevant to nuclear-grade graphite: review and recommendations. NASA/TM—2011-215805; 2011.

[12] Hodgkins A, Marrow TJ, Mummery P, Marsden B, Fok A. X-ray tomography observation of crack propagation in nuclear graphite. Mater Sci Tech-Lond 2006;22(9): 1045-51.

[13] Zou Z, Fok SL, Oyadiji SO, Marsden BJ. Failure predictions for nuclear graphite using a continuum damage mechanics model. J Nucl Mater 2004;324(2-3):116-24.

[14] Barenblatt GI. The mathematical-theory of equilibrium cracks in brittle-fracture. Adv Appl Mech 1962;7:55-129.

[15] Hillerborg A, Mode'er M, Petersson PE. Analysis of crack formation and crack growth in concrete by means of fracture mechanics and finite elements. Cem Concr Res 1976;6(6):773-81.

[16] Xu XP, Needleman A. Numerical simulations of fast crackgrowth in brittle solids. 
J Mech Phys Solids 1994;42(9):1397-434.

[17] Costanzo F, Walton JR. A study of dynamic crack growth in elastic materials using a cohesive zone model. Int J Eng Sci 1997;35(12-13):1085-114.

[18] Su RKL, Chen HHN, Kwan AKH. Incremental displacement collocation method for the evaluation of tension softening curve of mortar. Eng Fracture Mech 2012;88:49-62.

[19] Dantec-Ettemeyer. ISTRA for Windows, Version 3.3.12; 2001. [20] Shah SP, Swartz SE, Ouyang C. Fracture mechanics of concrete: applications of fracture mechanics to concrete, rock and other quasi-brittle materials. Wiley; 1995.

[21] ASTM. Standard method of test for plane-strain fracture toughness of metallic materials (E-399-90); 1997.

[22] Nakayama J. A bending method for direct measurement of fracture energy of brittle material. Jpn J Appl Phys 1964;3:422-3.

[23] Mirhabibi A, Rand B, Baghshahi S, Zadeh RAB. Graphite flake carbon composites with a 'sinterable' microbead matrix - I. Mechanical properties. Carbon 2003;41(8):1593-603.

[24] Mirhabibi AR, Rand B. Graphite flake-carbon composites. II: Fracture behaviour, toughness, notch insensitivity and Weibull modulus. Carbon 2007;45(5):991-7.

[25] RILEM. TC 50-FMC fracture mechanics of concrete, determination of the 
fracture energy of mortar and concrete by means of three-point bend tests on notched beams. Mater Struct 1985;18(4):287-90.

[26] Sakai M, Yoshimura J, Goto Y, Inagaki M. R-Curve behavior of a polycrystalline graphite - microcracking and grain bridging in the wake region. J Am Ceram Soc 1988;71(8):609-16.

[27] Fazluddin S. Crack growth resistance in nuclear graphite. University of Leeds, Ph.D. thesis; 2002.

[28] Allard B, Rouby D, Fantozzi G, Dumas D, Lacroix P. Fracture behavior of carbon materials. Carbon 1991;29(3):457-68.

[29] Sze KY, Fan H, Chow CL. Elimination of spurious pressure and kinematic modes in biquadratic 9-node plane element. Int $J$ Numer Meth Eng 1995;38(23):3911-32.

[30] Preston SD, Marsden BJ. Changes in the coefficient of thermal expansion in stressed Gilsocarbon graphite. Carbon 2006;44(7):1250-7.

[31] Becker TH, Marrow TJ, Tait RB. Damage, crack growth and fracture characteristics of nuclear grade graphite using the Double Torsion technique. J Nucl Mater 2011;414(1):32-43.

[32] Ouagne P, Neighbour GB, McEnaney B. Controlled crack growth in an oxidized nuclear grade graphite. J Phys D Appl Phys 2004;37(22):3192-7. 
[33] Roelfstra PE, Wittmann FH. Numerical method to link strain softening with failure of concrete. In: Wittmann FH, editor. Fracture toughness and fracture energy of concrete; 1986. p.163-175.

[34] Oh-oka T, Kitsutaka Y, Watanabe K. Influence of short cut fiber mixing and curing time on the fracture parameter of concrete (in Japanese). J Struc Constr Eng, Trans AIJ 2000;529:1-6.

[35] Hordijk DA. Local approach to fatigue of concrete. Delft University of Technology, Ph.D. dissertation; 1991.

[36] Rice RW, Freiman SW, Becher PF. Grain-size dependence of fracture energy in ceramics. 1. Experiment. J Am Ceram Soc 1981;64(6):345-50.

[37] Rice RW, Freiman SW. Grain-size dependence of fracture energy in ceramics. 2. A model for noncubic materials. J Am Ceram Soc 1981;64(6):350-4.

[38] Eto M, Growcock FB. Effect of oxidizing environment on the strength of H451, Pgx and Ig-11 graphites. Carbon 1983;21(2):135-47.

[39] Sato S, Awaji H, Kawamata K, Kurumada A, Oku T. Fracture criteria of reactor graphite under multiaxial stresses. Nucl Eng Des 1987;103(3):291-300.

[40] Planas J, Elices M, Guinea GV. Measurement of the fracture energy using three-point bend tests: Part 2-Influence of bulk energy dissipation. Mater Struct 1992;25(5):305-12. 
[41] Eto M, Ishiyama S, Burchell TD, Yahr GT. Biaxial strength and fracture criterion for HTGR graphites. J Nucl Sci Technol 1997;34(5):476-83.

[42] Yoon JH, Byun TS, Strizak JP, Snead LL. Characterization of tensile strength and fracture toughness of nuclear graphite NBG-18 using subsize specimens. J Nucl Mater 2011;412(3):315-20. 